\title{
Litwani et rex eorum ad fidem convertuntur Cristi. Die Wahrnehmung Litauens und der Litauer im mittelalterlichen Schlesien
}

\section{"Litwani et rex eorum ad fidem convertuntur Cristi." The Perception of Lithuania and Lithuanians in medieval Silesia}

Wojciech Mrozowicz / wojciech.mrozowicz@uwr.edu.pl (ORCID: 0000-0002-4407-0698) Instytut Historyczny, Uniwersytet Wrocławski, Wrocław, PL

\begin{abstract}
In the contribution were shown threads devoted to Lithuania and Lithuanians, based on the data from the Silesian chronicles and annals that were written in Silesia in the Middle Ages. Considerable geographic distance and almost any direct contact caused relatively little interest in the presenting this subject by the Silesian chroniclers. A little more attention was paid in the connection with the baptism of the grand duke of Lithuania Jogaila, his accession to the Polish throne, and the Christianisation of Lithuanians. The victory of the Polish-Lithuanian troops over the Teutonic Knights in the battle of Grunwald in 1410 was also of interest of the historiographers.
\end{abstract}

\section{Keywords}

Middle Ages; Lithuania; Silesia; Poland; Historiography; Władysław II Jagiełło (Jogaila); Christianisation; the Battle of Grunwald in 1410 
Man hätte gedacht, dass die schlesische mittelalterliche Geschichtsschreibung, die erst im Spätmittelalter von der polnischen Historiographie losgelöst worden ist, ${ }^{1}$ ihr folgend die Problematik der Vergangenheit und Gegenwart Litauens und der Litauer ausführlich schildern wird. Das war aber nicht der Fall. Die ziemliche Fülle der diesbezüglichen Informationen der damaligen polnischen Annalistik und Chronistik weckten nicht das Interesse der schlesischen Geschichtsschreiber. In den schlesischen Geschichtswerken spiegelten sich weder erfundene, noch tatsächliche Ereignisse aus der Geschichte von Litauen wider. Dazu gehören die von Johannes Długosz dargestellten mythischen Anfänge der Litauer, die römischer Abstammung sein sollten, ${ }^{2}$ ferner - die zahlreichen Einfälle der Litauer in Polen und Masowien (mit einer Ausnahme), die Gründung des ersten litauischen Staates, die Taufe und Krönung von Mindaugas im 13. Jahrhundert. Auch die Vermählung Aldonas, der Tochter von Gediminas, mit dem künftigen Polenkönig Kasimir dem Großen 1325, erregte nicht die Aufmerksamkeit der schlesischen Geschichtsschreibung. Es sind darin fast keine Spuren einer Kenntnis der polnischen Chroniken zu finden, die die litauischen Angelegenheiten und besonders die litauischpolnischen Beziehungen umfangreich beschrieben, wie die Werke des erwähnten Johannes Długosz, des sog. Mierzwa, der Großpolnischen Chronik oder der Chronik von Janko von Czarnikau (Czarnków). ${ }^{3}$ Die einzige mir bekannte Ausnahme bildet der spätmittelalterliche Tractatulus contra Cruciferos, Regni Polonie invasores von Eryk Rozpierski von Bąkowa Góra und Straszęcin, ${ }^{4}$ dessen Verwendung von einem schlesischen Historiographen im Weiteren mehr Aufmerksamkeit geschenkt wird.

Die Geschichtsschreibung Schlesiens geht also in der Darstellung der litauischen Angelegenheiten ihren eigenen Weg. Bereits am Anfang soll festgestellt werden, dass aus ihrer Sicht das Litauen und die Litauer samt der Problematik ihrer Taufe und Christianisierung zu einem relativ entlegenen Thema wurden. Trotzdem lohnt es sich, alle diesbezüglichen Angaben ausführlicher darzustellen, um die Durchdringung des Wissens über die „letzten Heiden Europas“ in einer entfernten Region zu erkennen.

Als ein bedeutendes und das chronologisch älteste Ereignis, das von einem schlesischen Historiographen aufgezeichnet wurde, ist der litauische Einfall in Masowien im Jahre 1262 anzusehen, den der Verfasser der in der zweiten Hälfte des 13. Jahrhunderts niedergeschriebenen Annales Silesiae Superioris als verewigungswürdig betrachtete. Er

1 Über die schlesische Geschichtsschreibung im Mittelalter siehe Heck, Roman: Gtówne linie rozwoju średniowiecznego dziejopisarstwa śląskiego. Studia Źródłoznawcze 22, 1977, S. 61-75; Ders.: Uwagi o średniowiecznym dziejopisarstwie ślaskim. In: Ders. (Hg.): Średniowieczna kultura na Śląsku. Wrocław 1977, S. 7-19; KorTa, Wacław: Średniowieczna annalistyka ślaska. Wrocław 1966. Eine aktuelle Synthese in Vorbereitung.

2 Dlugossius, Joannes: Annales seu cronicae incliti Regni Poloniae. Liber decimus: 1370-1405. Textum recensuit Danuta Turkowska. Varsaviae 1985, S. 164-165. Siehe Orzet, Joanna: Historia - tradycja - mit w pamięci kulturowej szlachty Rzeczypospolitej XVI-XVIII wieku. Warszawa 2016, S. 69-96.

3 BŁ.Aszczyk, Grzegorz: Dzieje stosunków polsko-litewskich od czasów najdawniejszych do wspótczesności 1. Trudne początki. Seria Historia 191. Poznań 1998, S. 20. Über die Taufe Litauens bei Joannes Długosz zuletzt: Dygo, Marian: 'Rudis illa nacio et pannosa'. Concerning Jan Dtugosz's description of Lithuania's 1387 conversion in his Annals. In: Verbum movet, exemplum trahit. The emerging Christian community in the eastern Baltic. Acta Historica Universitatis Klaipedensis XXXIII, 2016, S. 99-119.

4 Henricus Sbignei de Gora [= Eryk Rozpierski de Bąkowa Góra]: Tractatulus contra Cruciferos, Regni Poloniae invasores. Hg. v. Oswald Balzer. Monumenta Poloniae Historica (= MPH) 4. Lwów 1884, S. 143-191. 
teilte in knappen Worten mit: „Im Jahre 1262 wurde Siemowit, Fürst in Ujazdów, getötet“. ${ }^{5}$ Der Schwerpunkt dieser Aufzeichnung wurde auf den Tod Siemowit I., des Fürsten von Masowien, gelegt, den er durch die Hände von Litauern (Litowani) erlitt. Dies geschah während des Einfalls der Litauer in Masowien, der als eine Vergeltung für die Unterstützung Siemowits bei dem Angriff der Ordensritter auf Litauen im Jahr zuvor beabsichtigt worden war. ${ }^{6}$ Es ist zu bemerken, dass die Ortschaft Jesdow (d.i. Ujazdów, Vorgängerin der künftigen polnischen Hauptstadt Warschau; heute ein Stadtviertel von Warschau) infolge des litauischen Einfalls eingenommen wurde. ${ }^{7}$ Schlesier waren vom Einfall von 1262 nicht berührt, aber der oberschlesische Annalist hielt ihn - wie man vermuten könnte - für wichtig und notierenswert, genauso wie seine klein- und großpolnischen Fachkollegen.

Ein anderer Angriff der Litauer mit Russen und Kumanen, in diesem Fall unter der Führung vom Herzog Boleslaus V. dem Schamhaften von Krakau, im Jahre 1271 auf Schlesien und das Land Lebus, ist der Aufmerksamkeit der schlesischen Geschichtsschreiber überraschenderweise völlig entgangen. Darüber informieren zwei Briefe des Breslauer Bischofs Thomas II. an den Erzbischof von Gnesen Janusz und Bischof von Posen Nikolaus vom 28. Juni 1271:

„Herzog von Krakau Boleslaus [...] marschierte mit zahllosen russischen, kumanischen und litauischen Kriegern feindlich in Schlesien ein und plünderte unsere Dörfer sowie auch die Dörfer anderer Kirchen unserer Diözese und der Diözese Lebus und vernichtete sie mit Feuer. Wir berichten mit großer Sorge, dass sie, nachdem sie die Türe der Kirchen aufgebrochen haben, alle Leute, die inmitten waren, völlig die Immunität der Kirchen brechend, elend herausziehen und diese vom selben Herzog und den Seinen in unserer Diözese töten, darüber hinaus zahlreiche Leute verwunden und unzählbare Christen, Jungen und Jungfrauen, Alte und Jüngere, ohne Rücksicht auf ihr Geschlecht und Alter, elend in Gefangenschaft nehmen und entführen (alle Übersetzungen aus dem Lateinischen sind vom Verfasser)."

5 Rocznik Górnoszlaski. In: MPH 3. Hg. v. August Bielowski. Lwów 1878, S. 715: MCCLXII Symouit, dux in Jesdow, a Litowinis occiditur; über die Annales Silesiae Superioris siehe KorTA, W.: Sredniowieczna annalistyka, S. 105-144.

6 Ebenda, S. 136-138; Bı.aszczyк, G.: Dzieje stosunków, S. 41-43; Teterycz-Puzio, Agnieszka: Przyczyny i cele najazdów litewskich na ziemie sandomierska $w$ XIII w. Rocznik Lubelski 35, 2009, S. 14; DiEs.: Ksiażęta mazowieccy wobec państwa litewskiego w XIII wieku - walka czy wspótpraca? Zapiski Historyczne 75, 2010, S. 16-17.

7 GieYsZToR, Aleksander: Jazdow - poprzednik Warszawy. In: Liber Iosepho Kostrzewski octogenario a veneratoribus dicatus. Red. Konrad Jażdżewski. Wrocław 1968, S. 502-516; Ders.: Działania wojenne Litwy w roku 1262 i zdobycie Jazdowa. In: Studia historyczne Stanisławowi Herbstowi na sześćdziesięciolecie urodzin w upominku uczniowie, koledzy, przyjaciele. Red. Emanuel Halicz. Zeszyty Naukowe Wojskowej Akademii Politycznej. Seria Historia 15. Warszawa 1967, S. 5-14.

8 Schlesisches Urkundenbuch (= SUb) 4: 1267-1281. Bearb. v. Winfried Irgang. Köln - Wien 1988, Nr. 124, S. 91: Boleslaus dux Cracouie [...] cum innumeris Ruthenorum, Comanorum et Lituanorum milibus [!] Slesiam invadendo hostiliter villas nostras et Lubucensis ecclesie aliarumque ecclesiarum nostre dyocesis spoliavit et incendio devastavit et, quod cum magno dolore referimus, ecclesiarum hostiis effractis et omnibus inde miserabiliter abstractis earum emunitate penitus violata per ipsum ducem et suos in nostra dyocesi multi sunt occisi, plures vulnerati et innumerabiles Christi fideles, iuvenes et virgines, senes cum iunioribus, in captivitatem miserabiliter sunt abducti non parcentes sexui vel etati. Vgl. ebenda, Nr. 126, S. 92 (Brief an den Posener Bischof Nikolaus), wo ähnliche Formulierungen zu lesen sind: Boleslaus dux [...] cum innumeris Ruthenorum, Comanorum et Lituanorum milibus [!] Slesiam invadendo hostiliter villas nostras et Lubucensis ecclesie aliarumque ecclesiarum nostre dyocesis 
Im Vergleich zu der erwähnten Aufzeichnung über die Ereignisse des Jahres 1262 reagierte die schlesische Geschichtsschreibung anders auf den Feldzug der Litauer gegen Brandenburg 1326, dem sie eine ziemlich umfangreiche Notiz gewidmet hat. In diesem Fall standen die Litauer an Seite des polnischen Königs Wladislaus Ellenlang. Die diesbezügliche Aufzeichnung beschließt die erste Fortsetzung der Annalen der Zisterzienser von Heinrichau (Annales Cisterciensium Heinrichoviensium), die in den späten zwanziger Jahren des 14. Jahrhunderts entstand..$^{9}$ Im Gegensatz zu der bereits erwähnten Aufzeichnung des oberschlesischen Annalisten wurde sie gewissermaßen eingehender bearbeitet und sparte nicht mit schockierenden Details:

\begin{abstract}
„Im Jahre des Herrn 1326 marschierten die litauischen Truppen in die Diözese Lebus ein. Sie sind von König von Krakau Wladislaus, der Ellenlang genannt wird, angeworben worden und haben ihr Land verlassen. In der Diözese Lebus nahmen sie eine große Menge von Christen gefangen und behandelten sie beklagenswert. Sie entehrten Frauen und Jungfrauen, auch durchbohrten sie schwangere und gebärende Frauen mit ihren Leibesfrüchten. Den Anderen wurden die Kehlen durchgeschnitten. Zahlreiche Leute wurden auf verschiedene Art und Weise getötet. Die Restlichen wurden an den Händen gefesselt und zu zehn oder mehr Personen verkettet, mit Kesseln und anderen am Hals angehängten Dingen elend in ihr Land [Litauen] weggeführt. "10
\end{abstract}

Die zitierte Aufzeichnung stellt die Litauer als verantwortlich für den Feldzug auf das Gebiet der Diözese Lebus dar, und der Polenkönig Wladislaus Ellenlang, hier abschätzig als König von Krakau (rex Cracouie) bezeichnet, wird als Anstifter des Angriffs erwähnt. Tatsächlich war der Feldzug Folge des polnisch-litauischen Bündnisvertrages, der um 1325 abgeschlossen und mit der erwähnten Vermählung Aldonas mit Kasimir, dem Sohn Wladislaus, gesichert worden ist. Obwohl die Ereignisse des Jahres 1326 einer scharfen Kritik in der damaligen westlichen Geschichtsschreibung unterzogen wurden, ${ }^{11}$ sind sie jedoch einfach politisch zu erläutern: im Hintergrund des Bündnisses stand die Absicht, den litauischen Staat zu christianisieren, was die päpstliche Kurie in Avignon und Papst Johannes XXII. unterstützt haben. Dazu sollte man daran erinnern, dass der Wittelsbacher Ludwig IV., der damalige römisch-deutsche König (ab 1328 Kaiser), dessen minderjähriger Sohn Ludwig V. Markgraftum Brandenburg regierte, ein unversöhnlicher Feind von Johannes war, denn der Papst stand dem polnisch-litauischen Angriff

spoliavit et incendio devastavit etc. Über diesen Einfall, ohne Berücksichtigung der Schlesien betreffenden Angaben, siehe BŁaszczyк, G.: Dzieje stosunków, S. 41-44; Teterycz-Puzio, A.: Przyczyny i cele, S. 14.

9 Rocznik cystersów henrykowskich. In: MPH 3, S. 699-704; über diese Annalen siehe KorTA, W.: Średniowieczna annalistyka, S. 237-247.

10 Rocznik cystersów, S. 703-704: Anno Domini $M^{\circ} C C C^{\circ} X X V I^{\circ}$ [1326] Lithwanorum exercitus de terra sua egressus cum conductu regis Cracouie Vlodezlai, qui appellatus est Loketh, intraverunt dyocesim Lubuczensem, in qua magnam multitudinem hominum christianorum captivam duxerunt et ipsos miserabiliter tractaverunt. Nam mulieres et virgines stupraverunt, pregnantes et parturientes cum suis fetibus transfixerunt, quibusdam guttura presciderunt, quamplures eciam diversis modis occiderunt, reliquos vero vinctis manibus et decem vel pluribus pariter copulatis et caldaribus et aliis diversis rebus ad colla ipsorum suspensis in terram suam miserabiliter abduxerunt. Über diesen Einfall siehe BŁaszczyк, G.: Dzieje stosunków, S. 138-140.

11 Grabski, Andrzej F.: Polska w opiniach Europy Zachodniej XIV-XV w. Warszawa 1968, S. 155-165. 
auf Brandenburg wohlwollend gegenüber. Zu den kritischen Aussagen der westlichen Historiographie gehört auch die Aufzeichnung des schlesischen Annalisten, der die grausame Behandlung der Christen von den heidnischen Litauern besonders hervorhob. Dagegen wurde die Teilnahme der christlichen Polen am Feldzug in den Annalen der Zisterzienser von Heinrichau stillschweigend übergangen.

Wie gesagt war Schlesien durch die Ereignisse des Jahres 1326 in keiner direkten Bedrängnis. Aber die schlesisch-polnischen Beziehungen waren zu dieser Zeit ziemlich stark gespannt. Den Breslauer Stadtrechnungen kann man entnehmen, dass der Breslauer Herzog Heinrich VI. und die Stadt Breslau einen Kriegszug zu der schlesisch-großpolnischen Grenze (Heinzendorf in der Gegend von Guhrau, poln. Witoszyce, und Punitz in Großpolen, poln. Poniec) gegen König Wladislaus Ellenlang und das polnisch-litauische Heer aufnahmen, um den Brandenburger Feldzug zu schwächen. Die Stadtrechnungen erlauben jedoch nicht festzustellen, ob es damals zwischen dem Breslauer und dem litauischen Heer zu irgendeinem Zusammenstoß kam. ${ }^{12}$ Darüber schweigen auch die damaligen schlesischen chronikalischen und annalistischen Quellen.

Die andere Fortsetzung der Annalen der Zisterzienser von Heinrichau enthält noch eine wertvolle Aufzeichnung, die die litauische Problematik berührt. Sie wurde in den letzten Jahren des 14. Jahrhunderts niedergeschrieben (ich habe sie als Quelle des Titelzitats des vorliegenden Beitrags benutzt). Sie berichtet über die Christianisierung der Litauer und ihres Königs:

„Auch im Jahre des Herren 1386 bekehren sich die Litauer und ihr König zum christlichen Glauben. Dieser König hat die Tochter des Königs von Ungarn unter der Bedingung der Bekehrung geheiratet. Und er wurde von dem Krakauer Bischof in Krakau getauft. Er wurde auch zum König derselben Provinz. Er war ein großer Eiferer des christlichen Glaubens und Unterstützer der Geistlichkeit. Und er hieß Wladislaus. "13

Diese Aufzeichnung ist besonders wichtig aus der Sicht unserer Tagung, die auf „das letzte heidnische Volk Europas“ Nachdruck legt. Das geschilderte Ereignis - die Bekehrung der Litauer samt ihrem König, dessen Name Jagiełło / Jogaila nicht erwähnt wird (in der Handschrift wurde jedoch Platz für spätere Ergänzung freigelassen) - beendet de facto die heidnische Periode in der Geschichte Litauens. Für die Darstellung des schlesischen Annalisten, unabhängig von den nicht eindeutigen Formulierungen, steht die

12 Henricus Pauper. Rechnungen der Stadt Breslau von 1299-1358, nebst zwei Rationarien von 1386 und 1387, dem Liber imperatoris vom Jahre 1377 und den ältesten Breslauer Statuten. Hg. v. Colmar Grünhagen. Codex diplomaticus Silesiae (= CDS) 3. Breslau 1860, S. 52; siehe auch Regesten zur schlesischen Geschichte 1316-1326. CDS 18. Breslau 1898, S. 287, 307-308. Darüber siehe z. B. Goliński, Mateusz: Wroctaw od potowy XIII do poczatków XVI wieku. In: Buśko, Cezary - Goliński, Mateusz - Kaczmarek, Michał - Ziątkowski, Leszek: Historia Wrocławia. Od pradziejów do końca czasów habsburskich 1. Wrocław 2001, S. 132-133.

13 Rocznik cystersów, S. 704: Item anno Domini $M^{\circ} C C C^{o}$ LXXXVI [1386] Litwani et rex eorum ad fidem convertuntur Cristi. Qui rex sub fide conversionis duxit filiam regis Vngarie. Et ab episcopo Cracouiensi in Cracowia baptizatur. Qui eciam optinuit regnum eiusdem provincie. Qui fuit selator fidei et cleri multum. Et vocatus est Vladislaus. Dieses Quellenzitat sowie auch andere Fragmente der schlesischen Annalen werden hier nach den noch unveröffentlichten Materialien eines Forschungsprojektes, das von mir geleitet wurde, zitiert. 
Christianisierung der Litauer an erster Stelle, deren Initiative - obwohl dies nicht direkt formuliert worden ist - zur litauischen Seite gehört. Die Heirat Jagiełłos mit der „Tochter des Königs von Ungarn“, das heißt der Tochter Ludwigs des Großen von Anjou Hedwig, scheint unter Vorbehalt der früheren Taufe darauf hinzudeuten, dass es in seinem Interesse gelegen hätte, was aber nicht näher bestimmt ist. Wollte er nur eine Ehefrau bekommen oder wollte er sich bekehren? Diese Fragen müssen in diesem Zusammenhang unbeantwortet bleiben, umso mehr dass die Information über die Ergreifung der Königswürde durch Jagiełło getrennt angegeben wurde. Es ist auch nicht ganz klar, was für ein Königreich sich unter der Bezeichnung „eadem provincia“versteckt. Geht es hier um Krakau, Ungarn oder Litauen? Darüber hinaus hat der Annalist einen sachlichen Fehler begangen, und zwar bezeichnet er irrtümlich den Krakauer Bischof als den Geistlichen, der dem litauischen König die Taufe gespendet hat, anstatt des Erzbischofs von Gnesen Bodzanta. Der Krakauer Bischof, damals Johannes Radlica, war dabei ähnlich wie der Posener Bischof Dobrogost nur eine Begleitperson. ${ }^{14}$

Die polnische Tradition, die dem wichtigsten Chronisten des spätmittelalterlichen Polens Johannes Długosz folgt, ist deutlich anders. ${ }^{15}$ Für ihn war die Lösung des Problems der polnischen Königsmacht am wichtigsten. Die Verantwortung für den Ablauf der Ereignisse lag in den Händen der hohen polnischen Adeligen (barones Poloniae), die die Verhandlungen mit der litauischen Seite geführt haben. Sie haben auch die Bedingungen formuliert, unter denen sich die Taufe Jagiełłos und die Bekehrung Litauens zum christlichen Glauben befand: Alle haben den Litauer [Jagiełło] unter der Bedingung angenommen, wenn er mit den ihm unterstehenden Gebieten zum christlichen Glauben übertritt. ${ }^{16}$

Es ist noch zu bemerken, dass die Aufzeichnung der Annales Cisterciensium Heinrichoviensium von einem der gegenwärtigen litauischen Literaturwissenschaftler und Schriftsteller Algimantas Bučys kürzlich analysiert worden ist. ${ }^{17}$ Seine Aufmerksamkeit hat der Begriff König (rex) der Litauer gefesselt. Bučys stellt fest, dass die schlesische Aufzeichnung ein Beweis für die Fortdauer der Benutzung des litauischen Königstitels seit der Zeit Mindaugas‘ ist. Für die Verdrängung dieses Titels sollte, laut Bučys, Johannes Długosz verantwortlich sein, der die litauischen Herrscher zielstrebig als Fürsten bezeichnet. Ich möchte mich hier auf keine Diskussion darüber einlassen. Aus der Perspektive meines Beitrags wäre die Betonung der untypischen Aussage der betreffenden Aufzeichnung einer schlesischen Quelle, der Annales Cisterciensium Heinrichoviensium, am wichtigsten.

Die Taufe Jagiełos wurde auch ziemlich ausführlich von dem Abt des Klosters der regulierten Chorherren des hl. Augustinus in Sagan Ludolf (gest. 1422) im ersten Teil der Klosterchronik, die als Catalogus abbatum Saganensium bekannt ist, betrachtet. Abt Ludolf widmete dem ihm zeitgenössischen König von Polen einen separaten Abschnitt

14 Siehe z.B. Krzyżaniakowa, Jadwiga - Ochmański, Jerzy: Wtadystaw II Jagietto. Wrocław 1990, S. 92-93.

15 Dlugossius, J.: Annales, S. 142-159 (zum Jahr 1385 und 1386).

16 Ebenda, S. 145: in Lithwanum omnes eo pacto consensere, si fidem Christianam cum terris sibi subiectis susceperit.

17 Bučys, Algimantas: Lietuviu karaliai ir Lietuvos karalystè de jure ir de facto Viduramžiu Europoje. Literatūrologine istoriniu šaltiniu ir istoriografijos analize, slaptai.lt. Lietuvos aktualiju portalas, 27. 5. 2017, https://slaptai.lt/ algimantas-bucys-lietuviu-karaliai-ir-lietuvos-karalyste-11/\#_ftn1 (aufgerufen am: 20. 5. 2019). 
- De rege Polonorum, in dem aber der königlichen Gemahlin Hedwig besondere Aufmerksamkeit geschenkt wurde. ${ }^{18}$ Er betonte, dass Jagiełło - ohne Nennung seines litauischen Namens und seiner litauischen Abstammung - ein heidnischer Fürst war. ${ }^{19}$ Ähnlich wie später Johannes Długosz, hob er die politische Initiative der Polen hervor, die sich einen Neubekehrten zu ihrem König machten.

Zum Problem der Taufe Jagiełłos und der Litauer in der schlesischen Geschichtsschreibung des Spätmittelalters kehrte Johannes Wettziger aus Patschkau (gest. nach 1497) zurück. Dieser an der Krakauer Universität ausgebildete regulierte Chorherr des hl. Augustinus, der während seines Klosterlebens keinen festen Platz finden konnte, war mit den drei schlesischen Niederlassungen des Ordens Glatz, Breslau und Sagan verbunden. Aus seiner Feder stammt eine kaum bekannte und bis heute nur teilweise edierte annalistische Kompilation zur Geschichte Polens. ${ }^{20}$ Die darin enthaltene Charakteristik Jagiełłos, die ungewöhnlich in Schlesien ist, erweckt besonderes Interesse, sowohl wegen ihres Umfangs, als auch ob ihrer positiven Einstellung zur Person des polnischen Königs:

„Im Jahre des Herrn 1386, am 12. Februar, kam Jagelno, der Großfürst Litauens mit großer Feierlichkeit nach Krakau und wurde mit großer Feierlichkeit empfangen. Und am nächsten Tag wurde er und sein Bruder von dem Krakauer Erzbischof Bodzantha getauft. Und bekam den Namen Wladislaus. Und so heiratete er Ludwigs Tochter Hedwig. Dieser König zeichnete sich durch die Tugenden aller seiner Vorgänger aus. Dank ihm wurden die Litauer zum christlichen Glauben bekehrt.

Wehe der Gemeinschaft, deren Beratungsgremien keine gottesfürchtigen und gelehrten Männer angehören, weil vernünftige Ratschläge in ihren Herzen wie in Häusern aus Elfenbein ruhen. Deswegen gründete dieser [König] die hochheilige Universität in Krakau, durch die das Königreich Polen wie mit Sternen erhellt wird, da der Mensch ohne Wissen wie ein Fuhrwerk ohne Kutscher ist. Er trinkt keinen Wein und Wodka, weil er nüchtern sein wollte. Herrscherwillkür besiegte nicht seine Standhaftigkeit und Klugheit, sondern die Stärke seines Mutes siegte, weil er dachte, dass es nichts Wichtigeres als Großmütigkeit gibt. Er wollte lieber von der Tugend abstammende Armut als Überfluss von der Hartnäckigkeit, wie er vorher Not litt, falls den Bedürftigen Hilfe oder den Verdienstvollen Belohnung verweigert war. Ihn zeichnete große Demut aus, weil ihm eine schwarze Tunika genügte. Dieser König, der mehr mehr auf Gottes Hilfe als auf militärische Gewalt vertraute, hat die stolzen Preußen und die Kreuzritter besiegt. Diese Kreuzritter waren bestrebt, ihn während des Konstanzer Konzils mit zahlreichen Anschuldigungen in üblen Verruf zu bringen, aber sie erreichten nichts. Sie konnten ihm das Leben nicht nehmen,

18 Catalogus abbatum Saganensium. In: Scriptores rerum Silesiacarum 1. Hg. v. Gustav Adolf Stenzel. Breslau 1835, S. 218; dazu siehe Grabski, A. F.: Polska, S. 204-205.

19 Catalogus abbatum, S. 218: Poloni eam [Hedwigem] auferentes duci, cuidam gentili sed tunc a primo baptizato forte, Vladislao vel Wolislao nomine, in conjugio copularunt ipsumque neophitum super se regem fecerunt, qui tenens regnum Polonie usque in diem istum habet et eandem regis filiam in uxorem, licet sterilem et sine prole.

20 Mrozowicz, Wojciech: Późnośredniowieczna kompilacja dziejów Polski (Nieznany przekaz Rocznika tzw. świetokrzyskiego nowego wraz z Traktatem Henryka z Góry 'Contra Cruciferos' w rękopisie Biblioteki Uniwersyteckiej we Wroctawiu I Q 411). In: Źródłoznawstwo i studia historyczne. Acta Universitatis Wratislaviensis 1112. Historia LXXVI. Wrocław 1989, S. 219-225; Ders.: Art. Wettziger, Johannes. In: Encyclopedia of the Medieval Chronicle. Ed. by R.G. Dunphy. Leiden - Boston 2010, Sp. 1501-1502. Die Edition des ersten Teiles der Kompilation siehe Ders.: Rękopis żagański. In: Monumenta Poloniae Historica. II-12: Rocznik świętokrzyski nowy. Ed. Anna Rutkowska-Płachcińska. Kraków 1996, S. 89-97. 
so versuchten sie ihn zu verleumden. Sowohl mit Dingen wie auch mit Worten Lärm [erfolglos] gemacht haben, weil diesem König nichts fehlte, was für die Natur freundlich, für die Tugend harmonisch und mit der Ehrlichkeit im Einklang war. Deswegen hat er den Namen Wladislaus, was sehr lobenswert bedeutet. "21

Diese Charakteristik, eigentlich ein Panegyrikus auf König Wladislaus Jagiełł, wurde in Anlehnung an das dritte Kapitel der Abhandlung Tractatulus contra Cruciferos, Regni Polonie invasores von Eryk Rozpierski von Bąkowa Góra und Straszęcin bearbeitet. ${ }^{22}$ Man soll dieses Werk als einen Versuch wahrnehmen, das Wissen über die Geschichte Polens und Litauens von Johannes Wettziger, einem ehemaligen Krakauer Studenten, nach Schlesien zu übertragen. Bei dieser Gelegenheit wurde die Taufe der Litauer erwähnt, die zu den wichtigsten Verdiensten Jagiełłos gezählt ist.

In der Aufzeichnung von Johannes Wettziger fehlt es einerseits an Exaktheit. Irrtümlich bzw. nicht präzise, aber gemäß seiner Hauptquelle, wurden einige Angaben angeführt - die Taufe Jagiełłos fand nicht am 13., sondern am 15. Februar statt; mit Jagiełło wurde nicht ein, sondern drei seine Brüder (Wigunt-Aleksander, Korygiełło-Kazimierz und Świdrygiełło-Bolesław) getauft; ${ }^{23}$ wie in den Annales Cisterciensium Heinrichoviensium wurde auch der Erzbischof von Gnesen Bodzanta fehlerhaft als Erzbischof von Krakau genannt; ${ }^{24}$ auch die Herkunft seines christlichen Namens Wladislaus wurde verdreht. Andererseits ist in Wettzigers Werk die in Schlesien einzigartige Information über die

21 Wrocław, Biblioteka Uniwersytecka, Hs. I Q 411, f. 2v: Anno Domini 1 CCC 86, 12 die februarii [12 II 1386], Jagelno dux magnus Litwanie venit cum solempnitate in Cracoviam et suscipitur cum solempnitate magna. Et $2^{a}$ die [13 II 1386] baptizatus est cum fratre suo per archiepiscopum Cracoviensem Bodzantham. Et nomen ei imponitur Wladislaus. Et sic ei Heduigis, filia Lodwici, matrimonialiter coniugatur. Hic rex omnium antecessorum virtutes in se habuit. Per hunc Litwani conversi ad fidem.

Ve communitati in consiliis agendis, in quo non sanctifici doctique viri resident, quia sana consilia in pectoribus scientificorum velut in domibus eburneis requiescunt. Ideo hic instituit studium sacrosanctum Cracoviense, per quod regnum Polonie ut per sidera illustratur, quia homo sine sciencia sit currus sine auriga. Hic nec vinum, nec siceram bibit, quia sobrius foret. Constancie et prudencie hunc non vincebat libido dominandi, sed robur animositatis vincebat, ut preter magnanimitatem nichil magnum putabat. Maluit ex virtute enim sibi nasci egestatem, quam ex tenacitate habundanciam, ut se prius egere pateretur, si egenos denegare subsidia vel bene merentibus non retribuere premia. In quo et humilitas magna, quia nigra tunicella ei sufficiebat. Hic rex confisus plus de Dei adjutorio, quam viribus prostravit superbos Brutenos et Cruciferos. Hunc illi Cruciferi in Consilio Constanciensi multis criminibus infamare nitebantur, sed nichil perfecerant. Cui vitam non poterant auferre nituntur infama. Quem rebus non verbis perstrepitur, quia huic regi nichil defuit, quod nature amicum, quod virtuti consonum, quod honestatis consententaneum. Ideo nomen Wladislaus, id est valdus laude [!, richtig: valde laudabilis].

22 Henricus SbigneI: Tractatulus, S. 170-172. Über das Werk und seinen Verfasser siehe Balzer, Oswald: Henryk z Góry i jego traktat przeciw Krzyżakom. In: Ders.: Studia nad prawem polskim. Poznań 1889, S. 177-263; Bukowski, Waldemar: Eryk Rozpierski z Góry Bąkowej i Straszecina, autor Tractatuli contra Cruciferos, Regni Poloniae invasores. In: Homines et societas. Czasy Piastów i Jagiellonów. Studia historyczne ofiarowane Antoniemu Gąsiorowskiemu w sześćdziesiątą piątą rocznicę urodzin. Red. Tomasz Jasiński - Tomasz Jurek - Jan M. Piskorski. Poznań 1997, S. 171-184.

23 Siehe vor allem Dlugossius, J.: Annales, S. 153-154. Vgl. WDowiszewski, Zygmunt: Genealogia Jagiellonów i domu Wazów w Polsce. Kraków 2017, S. 42-46.

24 Vgl. oben. 
propagandistischen Verleumdungsversuche gegen Jagieło während des Konstanzer Konzils zu finden, die sich jedoch als vergeblich erwiesen haben. ${ }^{25}$

Die litauischen Fürsten und ihre Beziehungen zu den schlesischen Herrschern betrifft nur eine einzige Aufzeichnung in den schlesischen mittelalterlichen Quellen, die in der sog. Ratiborer Chronik (oder Annales Ratiborenses) aus dem 15. Jahrhundert enthalten ist. ${ }^{26}$ Sie berichtet über Helene (gest. nach 2. März 1449), die Tochter des litauischen Fürsten Kaributas und Nichte Wladislaus Jagiełłos, die sich mit dem Troppau-Ratiborer Fürsten Johann II. dem Eisernen (aus dem Troppauer Přemyslidischen Hause, gest. 1424) verheiratet hat. Sie ist von dem Krakauer Bischof Peter Wysz aus Litauen zu Pless (Pszczyna) in Oberschlesien hingebracht worden, wo sie am 3. April 1407 angekommen ist. Leider berichtet die Ratiborer Chronik (und andere schlesischen Chroniken) nicht, ob diese Ehe irgendwelche Folgen für die schlesisch-litauischen Kontakte hatte. ${ }^{27}$

Die nächsten „litauischen“ Informationen der schlesischen spätmittelalterlichen narrativen Quellen berühren die Problematik der Schlacht bei Tannenberg / Grunwald 1410, dabei ist aus meiner Sicht die Teilnahme der Litauer daran besonders relevant. Die Schlacht, die in zahlreichen Werken der westlichen Geschichtsschreibung ihre Widerspiegelung gefunden hat, ${ }^{28}$ wurde auch in Schlesien nicht übersehen. Im Oderland überwiegen jedoch karge Erwähnungen der Schlacht in den historiographischen Werken, unter denen der Tractatus de longaevo schismate (Traktat über das lang andauernde Schisma) vom Saganer Abt Ludolf eine bemerkenswerte Ausnahme bildet. ${ }^{29}$ Seine Darstellung, die um 1417-1422 niedergeschrieben wurde, umfasst ziemlich allgemeine Informationen über den Krieg zwischen König Wladislaus und dem Großmeister des Deutschen Ordens. Sie scheinen völlig leidenschaftslos und neutral zu sein, lediglich könnte die misslungene Belagerung von Marienburg (Malbork), die auf die Unterstützung Gottes und Marias, der Schutzpatronin von Marienburg, zurückgeführt wurde, als Beweis dafür dienen, dass die göttliche Vorsehung die Ordensseite begünstigte. Die Litauer wurden in dieser Schilderung nicht genannt - sie verbergen sich hinter der allgemeinen Formulierung: das Heer von verschiedenen, fast zahllosen Menschen..$^{30}$

Viel Aufmerksamkeit widmete der Schlacht bei Tannenberg Ludolfs Fortsetzer Peter Weynknecht im zuvor genannten Catalogus abbatum Saganensium. Der Leser seines Berichtes empfindet eine gewisse Sympathie für die polnisch-litauische Seite, was vor allem

25 Zum Problem vgl. BAR, Přemysl: Diplomacie, právo a propaganda v pozdním středověku. Polsko-litevská unie a Řád německých rytírů na kostnickém koncilu (1414-1418). Brno 2017 (= Opera Facultatis Philosophicae Universitatis Masarykianae 477), S. 182-215.

26 Ratiborer Chronik. Mitgetheilt von A[ugustin] Weltzel. Zeitschrift des Vereins für Geschichte und Alterthum Schlesiens (= ZVGS) 4, 1862, S. 114-126, hier S. 117: Item anno MCCCCVII, dominica Quasimodogeniti [3 IV 1407], ducisa Helena, consors ducis Johannis secundi, fuit adducta de Lytwania in Plesnam per dominum Petrum episcopum Cracoviensem. Über das Werk siehe KonTA, W.: Średniowieczna annalistyka, S. 296-299.

27 Die Ratiborer Chronik berichtet nur, dass Helene im Jahre 1409 den künftigen Fürsten Nikolaus (V.) geboren hat, siehe ebenda.

28 Grabski, A. F.: Polska, S. 253-291.

29 Ludolfi Tractatus de longaevo schismate. Hg. von Johann Loserth. Archiv für Österreichische Geschichte 60, 1880, S. 442-443. Vgl. Grabski, A. F.: Polska, S. 268.

30 Ludolfi Tractatus, S. 443: exercitus diversorum hominum quasi innumerabilium. 
die folgende Darstellung der Ursachen der Niederlage der Ordensritter offenbart: Die preußischen Herren vertrauten zu sehr auf ihre Stärke und, gierig verlangend nach Blut, wollten sie nicht den angebotenen Frieden annehmen, ${ }^{31}$ und das obwohl sich Chorherr Weynknecht dessen bewusst war, dass auch heidnische Tataren, Litauen, Russen und andere orientalische Völker gegen den Deutschen Orden gekämpft haben. ${ }^{32}$ Eine solche Haltung in Schlesien war nicht offensichtlich, weil dessen Einwohner sowohl auf der Seite des Deutschen Ordens als auch auf der des polnisch-litauischen Staates an der Schlacht bei Tannenberg teilgenommen haben. ${ }^{33}$

$\mathrm{Zu}$ den genannten bescheidenen Erwähnungen der Annalisten, die im Laufe des 15 . bzw. zu Beginn des 16. Jahrhunderts niedergeschrieben wurden, gehört in erster Linie eine umfangreichere Aufzeichnung in der Ergänzung zu den schon uns bekannten $A n$ nales Cisterciensium Heinrichoviensium, ${ }^{34}$ ferner die Notizen der Annales Dominicanorum Wratislaviensium $^{35}$ und der zum Teil mit ihnen verwandten Annales magistratus Wratislaviensis, ${ }^{36}$ der Ratiborer Chronik ${ }^{37}$, die annalistischen Aufzeichnungen in einer Breslauer Sammelhandschrift als Ergänzung zum Chronicon von Martinus Polonus, ${ }^{38}$ in einer noch nicht edierten Fortsetzung der Historia Bohemica, Polonica et Silesiaca. ${ }^{39}$ Es ist charakteristisch, dass all diese Aufzeichnungen kurz und bündig redigiert wurden und die

31 Catalogus abbatum, S. 256-257, Zitat S. 256: Prutenorum domini nimium de sua fortitudine confidebant, nolentes pacem oblatam suscipere, avide sagwinem adversariorum sicientes.

32 Ebenda: [populi] infideles [...] Tartarorum, Littwanorum, Rutenorum et aliorum orientalium.

33 Pfotenhauer, Paul: Schlesier im Dienste des Deutschen Ordens im Jahre 1410. ZVGS 15, 1880, S. 203-213. Über die Teilnahme der Schlesier an der Schlacht bei Grunwald / Tannenberg siehe zuletzt eine populäre Auffassung anlässlich einer Ausstellung: Iмıюсzук, Ewelina - KaWкA, Wojciech: Ślazacy pod Grunwaldem. Rekonstrukcje przesztości. Katalog wystawy. Bytom 2017.

34 Rocznik cystersów, S. 704: Item anno Domini $M^{\circ} C C C C X^{o}$ supradictus rex obtinuit triumphum in Prussia, devastando terram recipiens civitates plurimas et castra in possessionem preter Marienburg. Ibi corruit magister Ordinis in bello cum plurimis cruciferis et aliis hospitibus quasi infinitis numero. Et istud bellum factum fuit in die Divisionis Appostolorum [15. Juli 1410].

35 Mrozowicz, Wojciech: Wokót Rocznika dominikanów wroctawskich. In: Święty Jacek i dziedzictwo dominikańskie. Red. Erwina Mateja - Anna Pobóg-Lenartowicz - Maria Rowińska-Szczepaniak. Opole 2008 , S. 177-184, hier S. 184: Item anno Domini millesimo quadragintesimo X [1410] fuit bellum magnum Prutenorum et Polonorum.

36 Rocznik magistratu wroctawskiego. Hg. v. August Bielowski. MPH 3. Lwów 1878, S. 680-688, hier S. 685: Anno Domini MCCCCX [1410] fuit bellum magnum Prutenorum et Polonorum, ubi Pruteni miserabiliter prostratia in bello succubuerunt.

37 Ratiborer Chronik, S. 117: Item anno MCCCCX, in die Divisionis Apostolorum [15. Juli 1410], factum est premaximum bellum inter Prutenos et Polonos, sed rex Polonie Jegelno [!] obtinuit victoriam et magister Prutenorum succubuit et interfectus est cum innumerabili populo.

38 Wrocław, Biblioteka Uniwersytecka, Hs. IV F 175. GrünHAGEN, [Colmar]: Annalistische Nachlese 1227-1450. ZVGS 8, 1868/1, S. 186: Pruteni interfecti circa festum Divisionis Apostolorum [15 VII 1410] ad 600 et multi alii. Über die Handschrift siehe Soszyński, Jacek: Kronika Marcina Polaka i jej średniowieczna tradycja rękopiśmienna w Polsce. Studia Copernicana 34. Warszawa 1995, S. 92-94 (aber ohne Nennung der Aufzeichnung).

39 Wrocław, Biblioteka Uniwersytecka, Hs. IV F 104: Eodem anno victi sunt Pruteni a rege Polonie feria quarta post Divisionem Apostolorum [16. Juli 1410] (fehlerhafte Datierung). Über das Werk siehe BLÁHOvÁ, Marie: Představy o společném piovodu Čechů a Poláků ve středověké historiografii. Historia Slavorum Occidentis 2(3), 2012, S. 234-254. 
Niederlage des Deutschen Ordens betonten, wobei von der Teilnahme der litauischen Kräfte an der Schlacht keine Rede ist.

Nur in den Annalen des Breslauer Chorherrn Sigismund Rosicz wurde Vytautas der Große (Wytoldus dux Lithuanorum) als Helfer (Adiutor) des polnischen Königs Wladislaus Jagiełło, neben dem König der Tataren (rex Thartarorum), angeführt. ${ }^{40}$ Es ist zu bemerken, dass eine fast wörtliche Erzählung über die Schlacht bei Tannenberg der Kompilation des Benedikt von Posen um die Wende des 15./16. Jahrhundert angeschlossen wurde. ${ }^{41}$ Die beiden Autoren Sigismund Rosicz und Benedikt von Posen sprachen sich, ähnlich wie Peter Weynknecht, für die polnisch-litauische Seite des Konflikts aus.

Die ziemlich seltenen Aufzeichnungen der schlesischen mittelalterlichen Annalen und Chroniken über die litauischen Angelegenheiten zeugen von ihrem geringen Interesse daran, was aus der relativ großen geographischen Entfernung zwischen Schlesien und Litauen (ca. $800 \mathrm{~km}$ zwischen Breslau und Vilnius) und den zufälligen gegenseitigen Kontakten resultieren könnte. Die langsam zunehmende Zahl der Erwähnungen über Litauen im Spätmittelalter stellt einen Beweis dafür dar, dass diese Erscheinung eine Folge der Eingliederung der Litauer und ihres Landes in das christliche Europa zu sein scheint.

\section{"Litwani et rex eorum ad fidem convertuntur Cristi." Vnímání Litvy a Litevců ve středověkém Slezsku}

Studie přibližuje způsob, jakým byla vnímána Litva a Litevci ve středověkých historiografických dílech vzniklých ve Slezsku. Značná zeměpisná odlehlost a téměř neexistující bezprostřední kontakty Slezska s Litvou zapř́ícinily, že slezští středověcí dějepisci projevovali nepatrný zájem o litevské záležitosti. Objevovaly se pouze stručné zmínky o litevských nájezdech směřujících do polských zemí a do Braniborska. Situace se změnila až poté, co se nechal litevský kníže Jagello pokřtít, nastoupil na polský trůn a Litva byla pokřtěna. O těchto událostech informovali ve svých spisech mimo jiné Ludolf Zaháňský a Johann Wetziger. Z Wetzigerova pera pochází rozsáhlá a výstižná Jagellova charakteristika. Větší zájem dějepisců vyvolalo také vítězství polsko-litevských vojsk pod vedením Vladislava Jagella v bitvě u Grunvaldu nad řádem německých rytíŕů v roce 1410. Je třeba poznamenat, že účast Litevců nebyla v jejich spisech vždy připomínána. Bez zajímavosti není fakt, že tyto nepř́iliš obsáhlé zmínky mají neutrální charakter.

40 RosiczII, Sigismundi: Gesta diversa transactis temporibus facta in Silesia et alibi. Hg. v. Franz Wachter. Scriptores Rerum Silesiacarum 12. Geschichtsschreiber Schlesiens des XV. Jahrhunderts. Breslau 1883, S. 43: Eodem anno 1410, in die Divisionis Apostolorum [15. Juli 1410], fuit prelium magnum in Prussia, in quo prostrati fuerunt Pruteni cum ipsorum adiuvatoribus Silesiis, Bohemis, Misnensibus et aliis per regem Polonie Wladislaum, qui adiutores habuit regem Thartarorum, Wytoldum ducem Lithuanorum et plures alios, existente tunc magistro Prussie Ulrico.

41 MPH 3, S. 558: Eodem anno [1410] fuit magnum prelium in Prussia, in quo prostrati fuerunt Pruteni cum ipsorum adiutoribus Szlesitis, Bohemis, Misnensibus et aliis per regem Polonie Wladislaum, qui adiutores habuit regem Thartarorum, Wytoldum ducem Litphanorum et plures alios, existente tunc magistro Prussie Ulrico. 
